\title{
Strategic Research on Innovation and Development of China's Cloud Computing Industry
}

\author{
Xiaokang Tan \\ Applied Mathematics and Economics Department, Sichuan Vocational and Technical College, \\ Sichuan, China
}

Keywords: cloud computing technology; industrial innovation; development strategy

\begin{abstract}
Cloud computing is the most important landmark innovation in the new round of IT revolution in the world. It has become a strategic key technology and basic innovation platform that will lead the future development of the information industry and the entire economy and society. Developing cloud computing and popularizing cloud computing services have many positive effects. Therefore, it is necessary to strengthen overall planning and coordination, improve the development environment and adhere to independent innovation, so as to promote the healthy, orderly and rapid development of China's cloud computing industry. This paper briefly analyzes the strategic significance of the development of cloud computing, conducts in-depth research and analysis on the innovation and development of China's cloud computing industry, and hopes to provide some reference and development for the improvement of cloud computing level and industrial innovation and development.
\end{abstract}

\section{Introduction}

At this stage, cloud computing has gradually developed into a strategic technology that will lead the future information industry and even the entire social and economic development, and is a major innovation mark of the new new computer revolution. As early as 2006, when Google proposed "cloud computing," the global cloud computing market began to enter a stable and rapid development path. In recent years, the world has made a comprehensive and in-depth understanding of the changes and development opportunities brought by cloud computing, and the research on cloud computing has been increasing. With the development of China's economy and the optimization of the industrial value chain, cloud computing has gradually entered the cloud computing application growth period from the development and cultivation stage. However, there is still a big gap compared with developed countries. Therefore, it is necessary to study in depth the road to promote the development of cloud computing technology and industrial innovation in China $^{[1]}$.

\section{The strategic significance of developing cloud computing}

The current breakthroughs in emerging technologies, the constant changes in the new market space, and the accelerated changes in the new organizational forms of various industrial entities 
constitute the main picture of the development of strategic emerging industries in various countries. Facing an era of global informatization, new industrial changes have set new requirements for the storage, transmission and processing of massive data. We need to adopt new business models and technological innovation models to cope with new changes in the industry. Cloud computing is the most important landmark innovation in the new round of IT revolution in the world. It has become a strategic key technology and basic innovation platform that will lead the future development of the information industry and the entire economy and society. Although the exact definition of cloud computing has been controversial since its inception, the definition of the National Institute of Standards and Technology (NIST) has been widely quoted. NIST believes that cloud computing is a model that provides ubiquitous, convenient, and on-demand access to configurable computing resources, such as networks, servers, storage, applications, and services, over the network, enabling rapid deployment and deployment. And only minimal management costs or service provider intervention is required ${ }^{[2]}$.

Cloud User can store, process, and utilize the required information data through a remote computer connected to the Internet with a small amount of resources. Based on the cloud computing infrastructure, not only can new services for resource virtualization be developed, but also the scope and efficiency of public administration agencies can be improved. Therefore, cloud computing is not only a major technological innovation, but also a business model innovation. The Internet industry chain and its service model under cloud computing have created profound opportunities for change in the global information industry, as shown in Figure 1. The development of cloud computing technology and industry has important strategic significance for Chinese IT enterprises to break through the inherent technical barriers of multinational corporations, develop high-value-added emerging industries with international competitiveness, promote innovation and entrepreneurship based on cloud computing, and adjust and upgrade traditional superior industries.

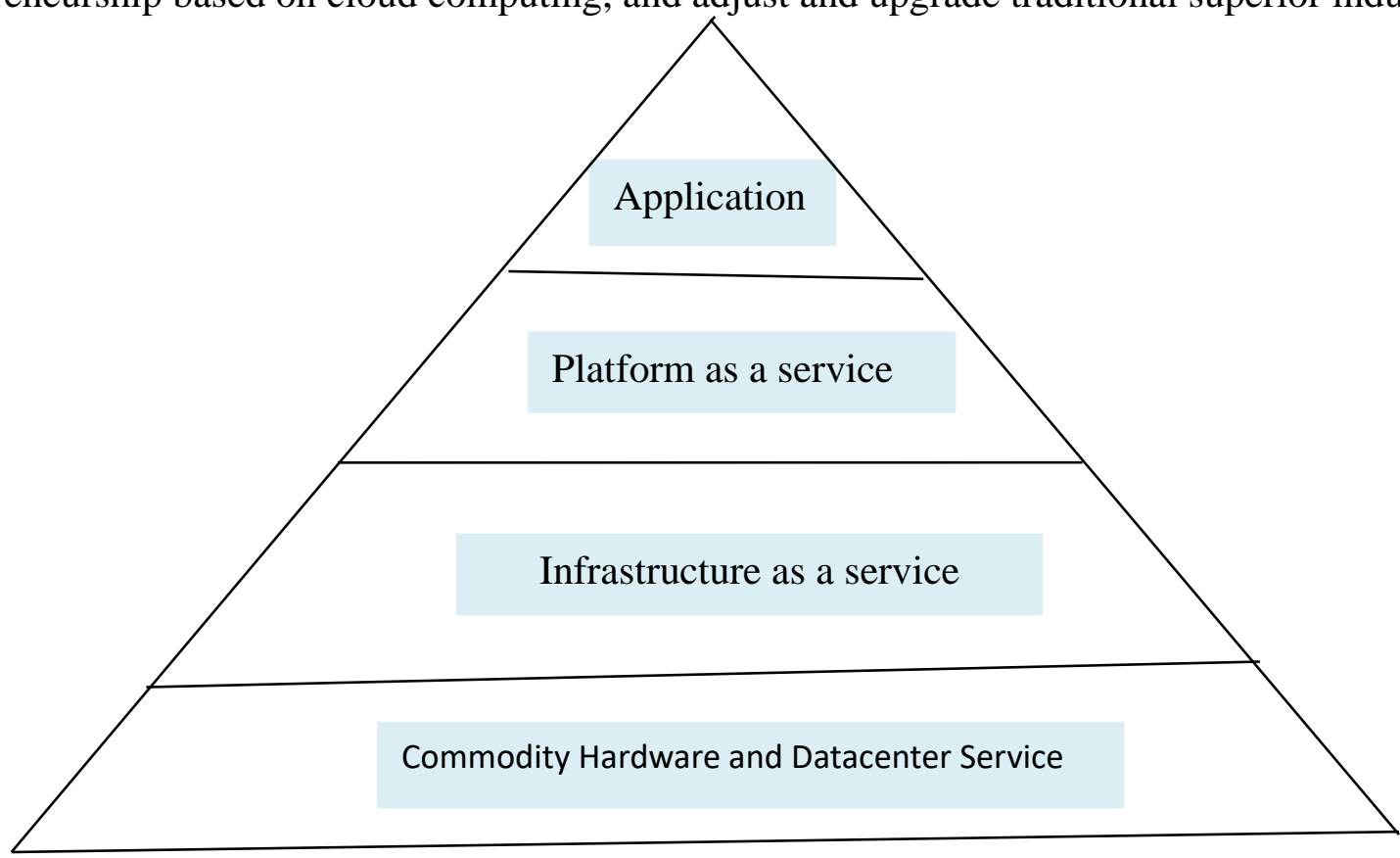

Figure 1 Internet industry chain under cloud computing 


\section{Measures to promote the innovation and development of China's cloud computing industry}

\subsection{Develop autonomous and controllable cloud computing core platform system}

The development of the core platform system of independent and controllable cloud computing has greatly promoted and promoted the development of cloud computing technology and industrial innovation in China. On the one hand, through the special funds of science and technology and government grants, it can help enterprises to establish independent technology systems, realize development and progress in computing, network, operation and maintenance, storage, etc., so that the level of big data analysis has been significantly improved and improved. On the other hand, lead more social capital to develop cloud computing applications in key areas. Promote the development of the overall technology through open source innovation and other advantageous enterprises. Help enterprises to increase their application and investment in the field of big data on the basis of the original business, and realize the deep application of cloud computing in the industry ${ }^{[3]}$.

\subsection{Cultivate innovative talents in cloud computing}

China needs to improve the training of innovative talents in cloud computing, formulate targeted talent training programs, and build relevant cloud computing experimental platforms to improve the quality and effectiveness of talent training, and ensure that talents can meet the cloud computing big data business model and The combination of traditional business models. In the long run, we will increase investment in computing science, establish a long-term computing science research center, open a big data computing discipline in universities, and improve China's cloud computing big data education system.

\subsection{Breaking cloud computing application limits}

Increase the application and promotion of cloud computing, improve people's cognitive level in cloud computing, and establish a perfect certification evaluation system according to the relevant standards of the innovation alliance. With the advent of the era of cloud computing big data, the cluster scale has shown a rapid growth state, achieving dynamic management of cloud computing platforms and improving service levels. Combining the actual needs of market development, leading the integration and development of new technologies. In terms of public institutions, it is necessary to change the development model, from the purchase of computing equipment in the past to the purchase of new computing services, and to develop cloud computing services toward government clouds and education clouds. Figure 2 shows the scale of China's cloud computing market in 2012-2018.

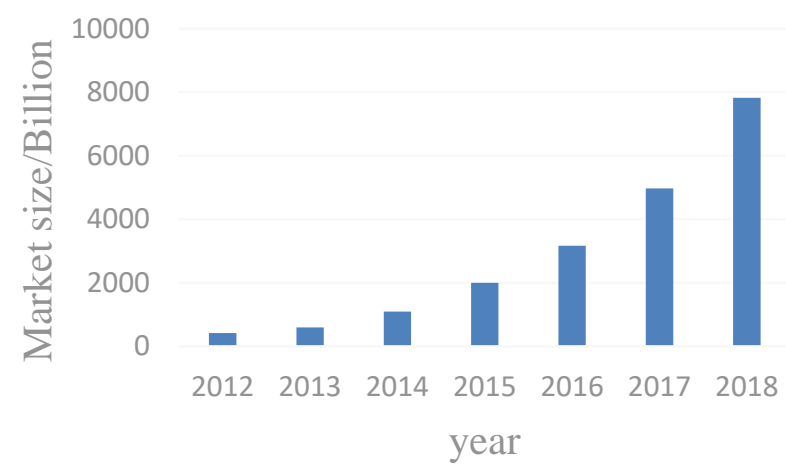

Figure 2 China's cloud computing market scale in 2012-2018 


\subsection{Provide a good policy environment for the development of cloud computing}

The development of cloud computing is mainly affected by security factors. Establish a sound information security system, improve the management level of data flow, establish user data information protection system for enterprise users and government users, implement the responsibility of data information service units, and pursue their responsibilities once security issues arise. At the same time, vigorously promote industry self-discipline, starting from cloud service enterprises and internet enterprises, and establishing industry self-discipline mechanisms for cloud service users. Improve the existing cloud computing standard system, optimize the broadband network environment, and guide the telecom operators to establish a cloud computing data center in the process of building a broadband network in combination with actual operational requirements, and improve the scientific rationalization of the network layout. The layout of a good backbone network to optimize the network interconnection architecture ${ }^{[4]}$.

\subsection{Optimize cloud computing resource service model}

At this stage, the level of cloud computing and the level of big data processing have been greatly improved, which has greatly enhanced the effective alliance between cloud computing and other related service industries. On the one hand, it can support the establishment of some high-level public cloud computing service enterprises, so that the cloud computing system service level and integration level can be significantly improved and improved. For larger enterprises or organizations, they can encourage the opening of platform resources and establish A win-win cloud computing service environment; On the other hand, increase the development of public cloud computing services, expand and enrich the current types of individuals and small and medium-sized enterprises cloud computing services, and improve the development speed of related industries ${ }^{[5]}$.

\section{Conclusions}

The development of cloud computing technology has played a great role in promoting China's social and economic development. Current our country in the aspect of the development of cloud computing also has certain problem, in order to promote the development of cloud computing technology in China and the industry innovation, first of all to develop independent controllable cloud computing core platform system, secondly to cultivate innovative talents, cloud computing also need to break the cloud computing application, provide a good policy environment for the development of cloud computing, and finally to optimize cloud computing resources service mode, improve the level of cloud computing technology development in our country, realize the industry innovation and development.

\section{References}

[1] Yu Jiang, Wan Jinbo, Zhang Yue. Strategic Thinking on Promoting China's Cloud Computing Technology and Industrial Innovation Development [J]. Chinese Journal of Academy of Sciences, 2015(2).

[2] Gong Qiang. Summary of Research on Cloud Computing Development in China [J]. Information Technology, 2013(7):1-4.

[3] Fang Gang. Research on the Strategic Development of Cloud Computing Business Application Model in China [D]. Beijing University of Posts and Telecommunications, 2012.

[4] Liu Yongyan, Hu Qiongjing, Xiao Rong. Analysis and Suggestions on Innovation of Cloud Computing Industry in China [J]. Software Guide, 2015, 14(7):1-4.

[5] Jing Jing, He Bo, Tang Gang, et al. Current status and development trend of China's cloud computing industry [C]// Broadband China Strategy and Innovation Symposium. 2012. 